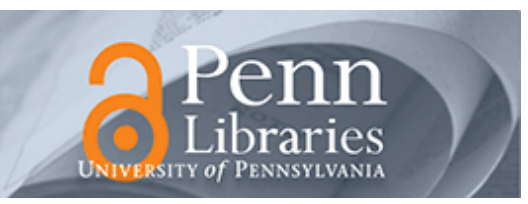

University of Pennsylvania

ScholarlyCommons

August 2002

\title{
Early Stages on the Graphitization of Electrostatically Generated PAN Nanofibers
}

\author{
Yu Wang \\ University of Pennsylvania, wangyu@seas.upenn.edu \\ Jorge J. Santiago-Aviles \\ University of Pennsylvania, santiago@seas.upenn.edu
}

Follow this and additional works at: https://repository.upenn.edu/ese_papers

\section{Recommended Citation}

Yu Wang and Jorge J. Santiago-Aviles, "Early Stages on the Graphitization of Electrostatically Generated PAN Nanofibers", . August 2002.

Copyright 2002 IEEE. Reprinted from Proceedings of the 2002 2nd IEEE Conference on Nanotechnology (IEEENANO 2002), pages 29-32.

This material is posted here with permission of the IEEE. Such permission of the IEEE does not in any way imply IEEE endorsement of any of the University of Pennsylvania's products or services. Internal or personal use of this material is permitted. However, permission to reprint/republish this material for advertising or promotional purposes or for creating new collective works for resale or redistribution must be obtained from the IEEE by writing to pubs-permissions@ieee.org. By choosing to view this document, you agree to all provisions of the copyright laws protecting it.

This paper is posted at ScholarlyCommons. https://repository.upenn.edu/ese_papers/198

For more information, please contact repository@pobox.upenn.edu. 


\title{
Early Stages on the Graphitization of Electrostatically Generated PAN Nanofibers
}

\begin{abstract}
Carbon nanofibers were produced from polyacrylonitrile/N, N-Dimethyl Formamide (PAN/DMF) precursor solution using electrospinning and vacuum pyrolysis at temperatures from $773 \mathrm{~K}$ to $1273 \mathrm{~K}$ for $0.5,2$, and 5 hours, respectively. Their conductance was measured. It was found that the conductivity increases sharply with the pyrolysis temperature, and increases considerably with pyrolysis temperatures of 873 , 973 and $1073 \mathrm{~K}$, but varies, less obviously, with pyrolysis time at the higher pyrolysis temperatures of 1173 and $1273 \mathrm{~K}$.

\section{Comments}

Copyright 2002 IEEE. Reprinted from Proceedings of the 2002 2nd IEEE Conference on Nanotechnology (IEEE-NANO 2002), pages 29-32.

This material is posted here with permission of the IEEE. Such permission of the IEEE does not in any way imply IEEE endorsement of any of the University of Pennsylvania's products or services. Internal or personal use of this material is permitted. However, permission to reprint/republish this material for advertising or promotional purposes or for creating new collective works for resale or redistribution must be obtained from the IEEE by writing to pubs-permissions@ieee.org. By choosing to view this document, you agree to all provisions of the copyright laws protecting it.
\end{abstract}




\title{
Early Stages on the Graphitization of Electrostatically Generated PAN Nanofibers
}

\author{
Yu Wang, Jorge J. Santiago-Aviles (Department of Electrical and Systems Engineering, University of \\ Pennsylvania, Philadelphia, PA 19104)
}

\begin{abstract}
Carbon nanofibers were produced from polyacrylonitrile/N, N-Dimethyl Formamide (PAN/DMF) precursor solution using electrospinning and vacuum pyrolysis at temperatures from $773 \mathrm{~K}$ to $1273 \mathrm{~K}$ for $0.5,2$, and 5 hours, respectvely. Their conductance was measured. It was found that the conductivity increases sharply with the pyrolysis temperature, and increases considerably with pyrolysis time at the lower pyrolysis temperatures of 873,973 and $1073 \mathrm{~K}$, but varies, less obviously, with pyrolysis time at the higher pyrolysis temperatures of 1173 and $1273 \mathrm{~K}$.
\end{abstract}

\section{INTRODUCTION}

Electrostatic generation, or electrospinning, of ultrafine fibers has recently stimulated much interest in the research community. So far, the technique has been mostly used to produce ultrafine polymer fibers [1-3]. Chun et al [4] and Wang et al [5] pyrolyzed electrospun polyacrylonitrile (PAN) fibers in the vacuum into carbon nanofibers, whose diameter is in the range of $100 \mathrm{~nm}$, much less than that of carbon fibers produced by other methods of spinning [68]. Wang et al [9] also synthesized ultrafine PZT fibers by sintering electrospun metal alkoxide fibers. Because of their high specific surface area, electrospun ultrafine fibers can be used as high performance filters, scaffolds in tissue engineering, and sensors. These possible applications become possible only after enough knowledge of the electrostatically generated fibers is gained. However, many properties remained to be uninvestigated. Take electrical conductivity as an example. Although it is very important in sensor application, so far only a few investigators have looked into it. Norris et al [10], using the indirect four-point probe method, measured the conductivity of their elctrospun non-woven ultra-fiber mats of polyaniline doped with camphorsulfonic acid blended with polyethylene oxide (PEO). MacDiarmid et al [11] obtained I-V curves of single 50wt\%PAn.HCSA/PEO fibers. The lack of conductivity data of electrospun carbon nanofibers can, to a large degree, be attributed to the difficulties in evaluating the cross-section area of the fibers. The authors evaluated the cross-section area using scanning probe microscope (SPM), and measured the room temperature electrical conductivity of PAN-based carbon nanofibers before [5]. This paper reports pyrolysis temperature and time dependence of the electrical conductivity evolution of carbon nanofibers.

\section{EXPERIMENT}

Commercial PAN powder and N, N-Dimethyl Formamide (DMF), in a ratio of $800 \mathrm{mg}$ PAN to $10 \mathrm{~cm}^{3}$ DMF, were used to prepare the precursor solution. Thermal gravimetric analysis (TGA) and thermal differential analysis (DTA) were conducted in Argon atmosphere, using SDT 29600 Simultaneous DTA-TGA analyzer, from room temperature to $1573 \mathrm{~K}$ at a heating rate of $10 \mathrm{~K} / \mathrm{minute}$.

The electrospinning was conducted in a homemade setup reported in details previously [5]. Before the deposition, arrays of $1 \mathrm{~mm} \times 1 \mathrm{~mm}$ or $50 \mu \mathrm{m} \times 50 \mu \mathrm{m}$ gold contacts were fabricated onto the surface of single crystal silicon substrates using lithography and vacuum evaporation. The deposition was conducted carefully so that only single fibers ran between two neighboring isolated gold contact pads.

The as-deposited samples were pyrolyzed in a Brew Model 466-S vacuum furnace at 773, 873, 973, 1073, 1173 and $1273 \mathrm{~K}$ for $0.5,2$ and 5 hours, respectively. The vacuum was maintained at pressures lower than $1.33 \times 10^{-4}$ $\mathrm{Pa}$. The substrates, with $50 \mu \mathrm{m} \times 50 \mu \mathrm{m}$ gold contact pad arrays, were used only for fibers pyrolyzed at 773 and $873 \mathrm{~K}$. All other samples, pyrolyzed at higher temperatures, used $1 \mathrm{~mm} \times 1 \mathrm{~mm}$ gold contact pad arrays.

An H-P Model 4145B Semiconductor parameter analyzer was used to measure the I-V characteristics of the carbon nanofibers at room temperature. The testing voltage ranged from $-20 \mathrm{~V}$ to $20 \mathrm{~V}$, with the step of $0.1 \mathrm{~V}$. The measurement was conducted on the same segment of fiber for 10-20 times under the same conditions.

Optical microscope was used to observe the fiber after pyrolysis and measured their length 1 . Digital Instruments Dimension 3000NS-III SPM, operated in tapping mode, was used to record the height and amplitude images of fibers as data files. Offline image processing software was used to obtain the average cross-section profile, from which cross-section area was evaluated. To ensure reliable results, a scanning electron microscope (SEM) was used to record the image of fibers, from which the horizontal diameter of the imaged fibers was also evaluated. The gold contact pads served as excellent internal length references. The conductivity was finally determined using 
$\sigma=\mathrm{GS} / \mathrm{l}$, where $\mathrm{G}, \mathrm{S}$ and 1 are conductance, average crosssection area and the length of the fibers, respectively.

\section{Results \& Discussions}

The TGA-DTA curves (Fig. 1) show a dramatic weight loss and an endothermic DTA peak between room temperature and $473 \mathrm{~K}$, indicating the solvent (DMF) evaporation. Beyond this temperature, a broad exothermic peak appear in DTA curve (Fig 1b) and weight decreases at a much slower rate, from $8.34 \%$ at $473 \mathrm{~K}$ to $3.88 \mathrm{wt} \%$ at $873 \mathrm{~K}$, and to $3.35 \mathrm{wt} \%$ and $2.62 \mathrm{wt} \%$ at 1273 and $1573 \mathrm{~K}$, respectively. It is noteworthy that a small sharp peak, centered at $570 \mathrm{~K}$, is superimposed on the broad exothermic DTA peak.
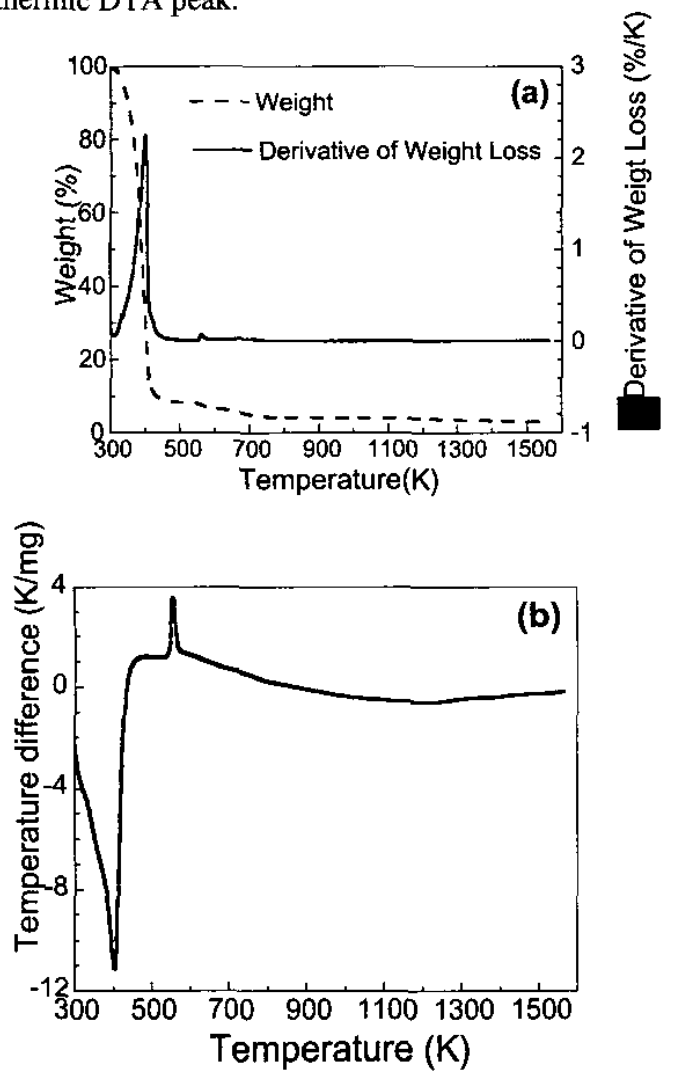

Fig. 1 TGA (a) and DTA (b) curves of the precursor PAN/DMF solution

Fig. 2 shows the I-V curves of carbon fibers pyrolyzed at different temperatures for half hour periods. Their linearity implies an ohmic contact between the contact pad and the fibers. The linear slope, or the conductance of the fibers, $G$, increases sharply with the pyrolysis temperature.
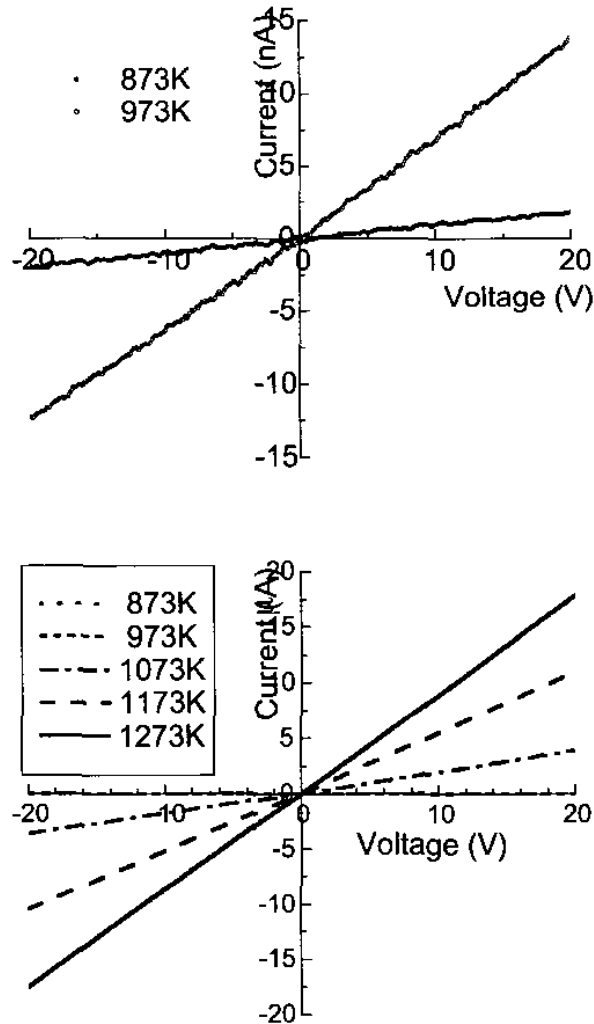

Fig. $2 \mathrm{I}-\mathrm{V}$ curves of carbon nanofibers pyrolyzed at different temperatures

Fig. 3 shows SPM height and amplitude images of a typical single fiber. The apparent semicircular profile of the cross section (Fig 3c) may be misleading because the cone-shaped tip could not track the lower half of the cross section (Fig. 3d). However, the height of the fiber, or the vertical diameter, is real. The full width at half maximum (FWHM) was taken as the horizontal diameter of the fibers. Since the measured values of vertical and horizontal diameters on the same cross section are different, and the cross section is elliptical rather than circular, as previously supposed. 


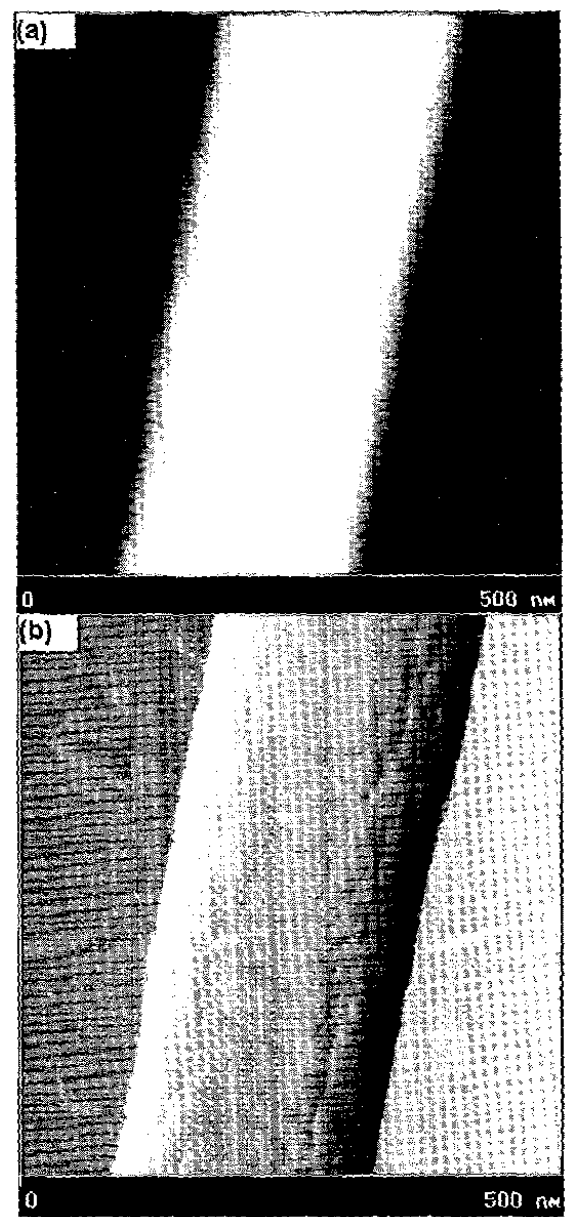

(c)

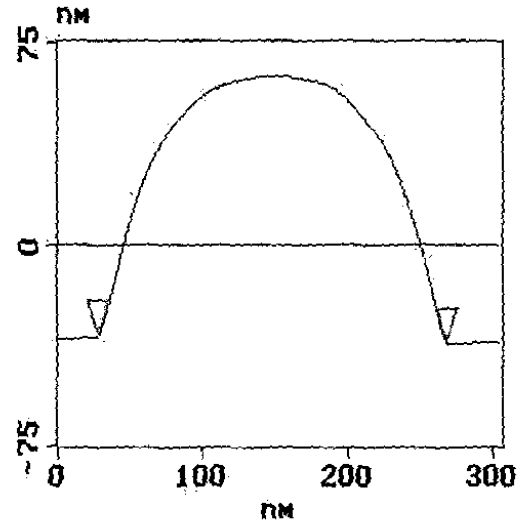

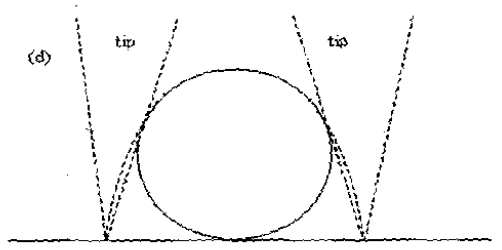

Fig. 3 SPM micrograph of carbon nanofiber and its cross section profile

SEM image of the fiber revealed by SPM in Fig. 3 also reveals its irregularity (Fig. 4). The average horizontal diameter of the fiber was measured to be $120 \mathrm{~nm}$, approximately the same as the FWHM value obtained from SPM cross-section profile, justifying the use of FWHM as the hotizontal diameter. This paper uses the diameter values measured from SPM height images since they give both horizontal and vertical diameters.

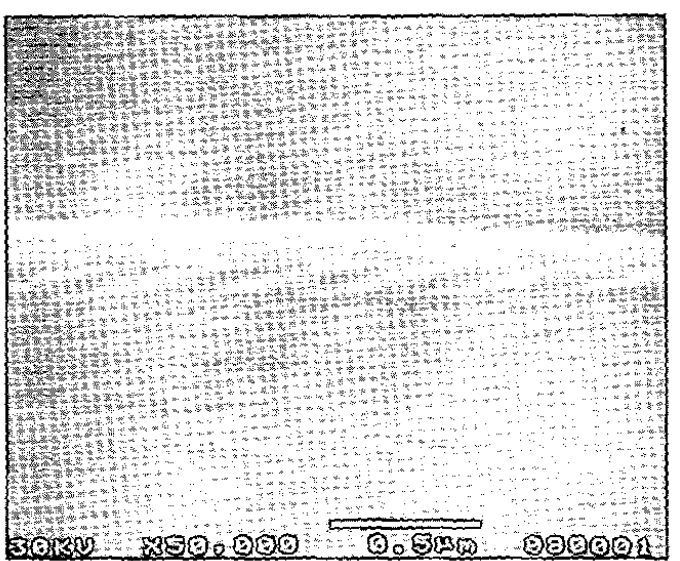

Fig. 4 SEM image of the same fiber revealed by SPM in Fig. 3

Pyrolysis at $773 \mathrm{~K}$ did not generate a conductance high enough as to be detected. Since the detection limit of the measurement system is estimated to be $0.2 \mathrm{~S} / \mathrm{m}$, the conductance of the fibers pyrolyzed at $773 \mathrm{~K}$ must be lower than this value. At temperatures higher than $873 \mathrm{~K}$, the conductivity increases sharply with pyrolysis temperature. It also increases with the pyrolysis time at lower pyrolysis temperatures $(873,973$ and $1073 \mathrm{~K}$ ) (Fig $5 a)$, but levels off at higher pyrolysis temperatures (11731273K) (Fig. 5b). 


\section{CONCLUSION}
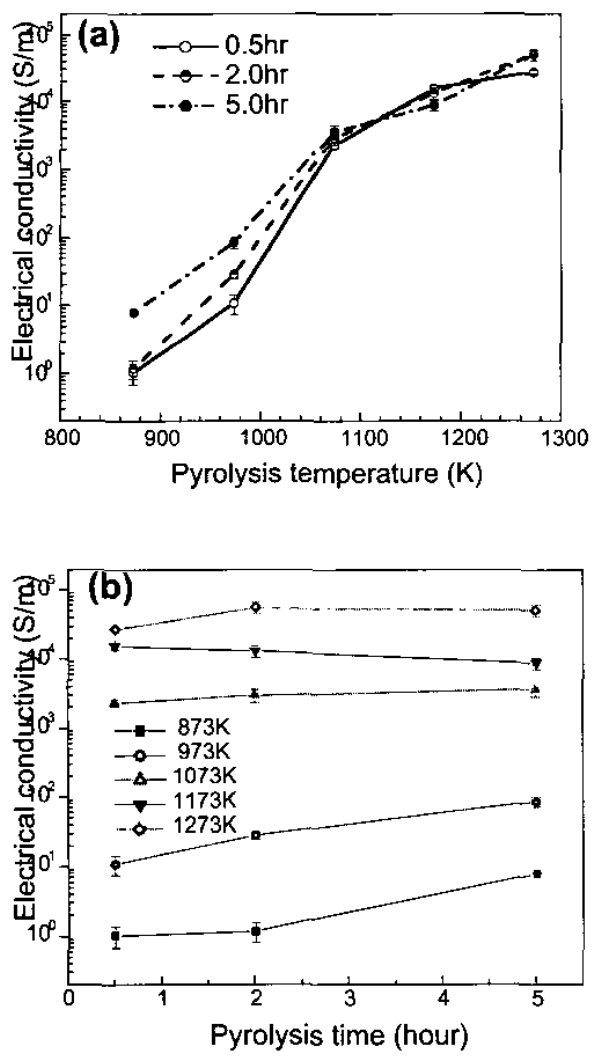

Fig. 5 Pyrolysis temperature (a) and time (b) dependence of the conductivity
The conductivity of PAN-based carbon nanofibers produced by electrospinning was measured. It increases sharply with the pyrolysis temperature, and also increases considerably with pyrolysis time at lower pyrolysis temperatures $(873,973$ and $1073 \mathrm{~K}$ ), but varies less obviously with pyrolysis time at higher pyrolysis temperatures (1173 and 1273K).

\section{REFERENCES}

[1] A. Formhals, US Patent No. 1,975,504, 1934.

[2] J. Doshi and D. H. Reneker, J. Electrost. 35 (1995) 151.

[3] D. H. Renker and I. Chun, Nanotechnology 7 (1996) 216.

[4] I. Chun, D. H. Reneker, H. Fong X. Famg, J Deitzel, N. B Tan,and K Kearns, J. Adv. Mater. 31 (1996) 36.

[5] Y. Wang, S. Serrano and J. J. Santiago-Aviles, "Conductivity measurement of electrospun PAN-based carbon nanofiber", Journal of Materials Science Letters, in press.

[6] L. H. Peebles, carbon fibers, Chapter 3, CRC Press, Boca Raton, Florida, 1995

[7] O. P. Bahl, Z. Shen, J. G. Lavin and R. A. Ross, "Chapter 1, Manufacture of Carbon Fibers", in Carbon Fibers edited by Jean-Baptiste Donnet, et al., 3rd ed., rev. and expanded, Marcel Dekker, New York, 1998.

[8] J.-P Issi and B. Nysten, "Chapter 6 Electrical Thermal Transport in Carbon Fibers", ibid.

[9] Y. Wang, S. Serrano and J. J. Santiago-Aviles, "Electrostatic Synthesis and Characterization of $\mathrm{Pb}\left(\mathrm{Zr}_{\mathbf{x}} \mathrm{Ti}_{1-\mathrm{x}}\right) \mathrm{O}_{3}$ Micro/nano-fibers", Syposium U: , MRS fall Meeting, Nov 25-31, 2001, Boston

[10] I. D. Norris, M. M. Shaker, F. K. Ko, and A. G MacDiarmid, Synthetic Metals 114 (2000) 109.

[11] A. G. MacDiarmid, W. E. Jones, Jr, I. D. Norris, et al, $\begin{array}{lll}\text { Synthetic Metals, } & 119 & \text { (2001)27-30 }\end{array}$ 